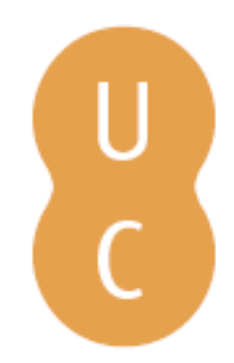

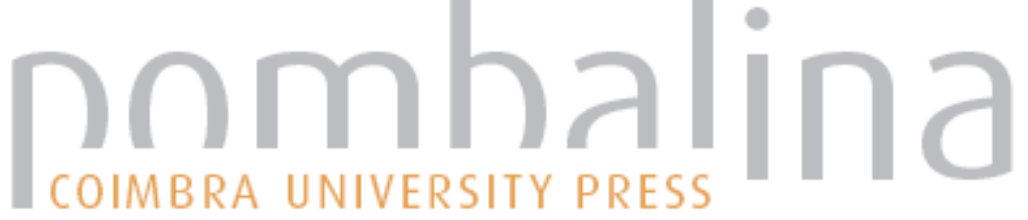

\section{Evolução da filosofia do sistema de limitação de dose e a questão das substituições "superseded"}

\author{
Autor(es): $\quad$ Correa, F.; Sordi, G.; Levy, D. S. \\ Publicado por: Imprensa da Universidade de Coimbra \\ URL \\ persistente: URI:http://hdl.handle.net/10316.2/44477 \\ DOI: $\quad$ DOI:https://doi.org/10.14195/978-989-26-1602-5_34 \\ Accessed : $\quad$ 26-Apr-2023 15:25:06
}

A navegação consulta e descarregamento dos títulos inseridos nas Bibliotecas Digitais UC Digitalis, UC Pombalina e UC Impactum, pressupõem a aceitação plena e sem reservas dos Termos e Condições de Uso destas Bibliotecas Digitais, disponíveis em https://digitalis.uc.pt/pt-pt/termos.

Conforme exposto nos referidos Termos e Condições de Uso, o descarregamento de títulos de acesso restrito requer uma licença válida de autorização devendo o utilizador aceder ao(s) documento(s) a partir de um endereço de IP da instituição detentora da supramencionada licença.

Ao utilizador é apenas permitido o descarregamento para uso pessoal, pelo que o emprego do(s) título(s) descarregado(s) para outro fim, designadamente comercial, carece de autorização do respetivo autor ou editor da obra.

Na medida em que todas as obras da UC Digitalis se encontram protegidas pelo Código do Direito de Autor e Direitos Conexos e demais legislação aplicável, toda a cópia, parcial ou total, deste documento, nos casos em que é legalmente admitida, deverá conter ou fazer-se acompanhar por este aviso.

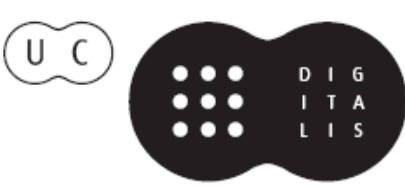




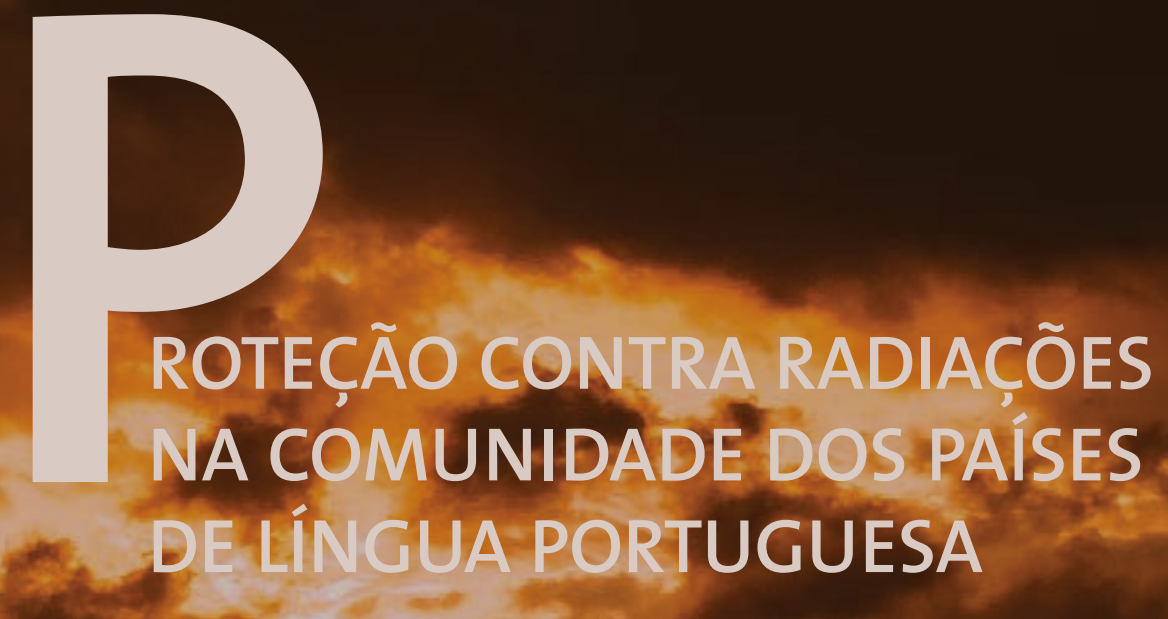

\section{ROTEÇÃO CONTRA RADIAÇÕES NA COMUNIDADE DOS PAÍSES DELINNGUA PORTUGUESA}

Luis Neves (coord.)

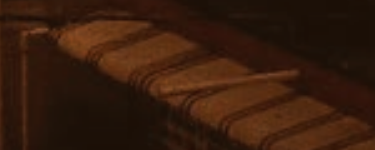




\section{EVOLUÇÃo da Filosofia do SISTEMA DE LIMITAÇÃo DE DOSE E A QUESTÃO DAS SUBSTITUIÇÕES “S UPE RS E D E D"}

\section{PHILOSOPHY EVOLUTION OF THE DOSE LIMITATION SYSTEM AND THE ISSUE OF REPLACEMENTS IN THE “SUPERSEDED” PUBLICATIONS}

F. CORREA - feliperc@usp.br (Universidade de São Paulo, Instituto de Pesquisa Energética e Nuclear-IPEN)

G. SORDI - gmsordi@ipen.br (Instituto de Pesquisa Energética e Nuclear, Comissão Nacional de energia Nuclear)

D. S. LEVY - denise@omiccron.com.br (Universidade de São Paulo, Instituto de Pesquisa Energética e Nuclear)

PALAVRAS-CHAVE: proteçcao radiologica, ICRP, IAEA, limites de dose, filosofia.

RESUMO: O grande avanço da era nuclear mostrou que a filosofia do sistema de limitação de dose proposta pela Comissão Internacional de Proteção Radiológica em 1958 e os Limites Anuais Máximos Permissíveis (LAMP), careciam de mudanças, assim, com a atualização das recomendações surgiu uma nova filosofia, ainda vigente, denominada de Limites Anuais Máximos Admissíveis (LAMA) para que possamos estuda-los separadamente, analisando cuidadosamente como surgiram estas filosofias e como foram evoluindo até as suas últimas publicações. 
Uma vez que cada nova publicação substituía a anterior, e a ICRP e o Organismo Internacional de Energia atômica (IAEA) firmaram o acordo pelo qual este último adotaria a filosofia proposta pela Comissão, houve a possibilidade que algumas destas informações, algumas valiosas, possam ter se perdido no decorrer da substituição da publicação e ou da edição da norma do IAEA na adoção da filosofia. Estas informações são discutidas e estudadas em profundidade e o seu valor real mostrado, levantando a possibilidade de reintroduzi-las nas futuras publicações.

KEYWORDS: radiation protection, ICRP, IAEA, dose limits, philosophy.

ABSTRACT: The breakthrough of the nuclear age showed that the philosophy of dose limitation systems proposed in 1958 by the Internations Comission on Radiation Protection and the Maximum Permissible Annual Limits lacked changes, thus, with the update of the recommendations a new philosophy appeared, still in force, called Maximum Allowable Annual Limits so we can study them separately, analyzing carefully how these philosophies have arisen and how have evolved to their latest publications. Since each new publication replaced the previous and the ICRP and the International Atomic Energy Agency (IAEA) agreed that the latter organism would adopt the philosophy proposed by the Commission, there was the possibility that some of this information, some valuable, may have disappeared during the replacement of the publication or edition of the standard of the IAEA in the adoption of philosophy. This information is discussed and studied in depth and their real value is shown, raising the possibility of reintroducing them in future publications. 


\section{INTRODUÇÃo}

Em 1928 durante o segundo Congresso Internacional de Radiologia realizado em Estocolmo foi fundada a ICRP - "International Comission on Radiation Protection" encarregada de estabelecer recomendações de proteção e segurança no campo das aplicações pacificas das radiações ionizantes.

Até a data de 1956, quando foi liberada a energia nuclear para os seus usos pacíficos, as recomendações da ICRP eram publicadas nas revistas cientificas internacionais de radiologia, pois as radiações ionizantes só eram era utilizadas no campo da medicina.

Com a liberação da energia nuclear para fins pacíficos, deixando de ser segredo de algumas poderosas nações detentoras do conhecimento cientifico da época, anteviu-se que o desenvolvimento do campo cientifico das radiações teria um crescimento colossal e seriam praticamente utilizadas por todas as nações. Em virtude disto a ICRP resolveu publicar as suas recomendações em compêndios próprios e não mais nas revistas de medicina pois a aplicação das radiações ionizantes se estenderia a muitos outros campos de conhecimentos técnico cientifico além da medicina.

Em virtude disso em 1958 a ICRP publicou o seu primeiro compendio de recomendações com o número 1. Estas recomendações foram completadas em 1959 com o compendio de número 2 que tratava das exposições internas ao corpo humano.

$\mathrm{Na}$ mesma época da liberação da energia nuclear para fins pacíficos, foi criado o "International Atomic Energy Agency", IAEA, órgão oficial da Organização das Nações Unidas para coordenar e orientar no desenvolvimento técnico cientifico do uso das radiações ionizantes e energia nuclear. Esta organização firmou um acordo com a ICRP de que no campo da proteção e segurança com relação à radiação ionizante adotaria a filosofia das recomendações do ICRP mas que editaria as suas próprias recomendações. 
Com o "boom" do desenvolvimento técnico cientifico anteviu-se que aquelas recomendações necessitavam de alterações e algum detalhamento, razão pela qual a publicação número 1 da ICRP foi substituída em 1996 pelo de número 9 e o IAEA resolveu editar em 1967 sua primeira edição na série "Safety Series" com o número 9.

\section{MÉTODOS}

Foi realizado um estudo profundo das publicações de número 1, 2, 9, 22, 26, 30, 60 e 103 da ICRP e das publicações 9, 9 (edição de 1982), 115 e GSR parte III para que possa ser entendido como as filosofias do sistema de limitação de dose foram evoluindo. Em seguida foi realizado um confrontamento entre as publicações 1 da ICRP com a publicação número 9 também da ICRP, publicação número 9 da ICRP com a publicação número 9 da ICRP, publicação número 9 da ICRP com a publicação número 9 do IAEA, publicação número 2 da ICRP com a publicação número 30 da ICRP, publicações número 1, 2, 9 da ICRP e publicação número 9 do IAEA com as publicações número 26 e 30 da ICRP e a publicação número 9 do IAEA (edição de 1982), publicação número 60 da ICRP com a publicação número 115 do IAEA, publicação número 103 da ICRP com a publicação número GSR parte III para identificar as informações análogas ou semelhantes, informações da ICRP que não constam no IAEA e informações do IAEA que não constam na ICRP.

\section{RESULTADOS}

Durante nossa investigação nas publicações pertinentes do IAEA e da ICRP foram encontradas as três categorias de informações: 
as análogas ou semelhantes, da ICRP que não constam no IAEA e informações do IAEA que não constam na ICRP. O estudo realizado foi por deveras extenso e aqui ressaltaremos algumas informações que julgamos suficientes para se fazer entender o estudo em questão. Iniciaremos na ordem cronológica das publicações pertinentes que se dá do confrontamento da publicação número 1 da ICRP com a de número 9 da ICRP.

Um grande avanço constatado em relação as duas publicações foi com relação as categorias de exposição, onde na publicação número 1 da ICRP encontramos as seguintes: a) Trabalhadores regularmente expostos à radiação; b) Trabalhadores ocasionalmente expostos a radiação e c) Membros do público. A publicação número 9 da ICRP, que fornece muito mais informações a respeito, reduz estas categorias para duas, a saber: A) Adultos expostos no decorrer de seu trabalho e B) Membros do público.

A redução das categorias de indivíduos expostos à radiação é um fator muito importante, pois a categoria (b) da publicação número 1 englobava visitantes, prestadores de serviços e manutenção e deviam obedecer aos limites de dose do público. Com a publicação número 9 estes grupos foram separados pois o grupo (A) engloba só os trabalhadores expostos no decorrer de seu trabalho e, portanto, foram excluídos os visitantes, prestadores de serviços e pessoal de manutenção que poderiam adentrar em áreas controladas quando não há a presença da fonte de exposição, os demais devem obedecer aos limites dos trabalhadores.

Com relação a Limitação da Dose, destacaremos algumas informações inovadoras que estão contidas somente na publicação número 9 da ICRP. Em situação de emergência o limite de dose dos trabalhadores para o corpo inteiro foi diminuído de 12 rem para 2 vezes o limite anual, isto é, $10 \mathrm{rem}$. O que não se justifica, pois vai contra a equação da idade evocada em muitas situações. Outro assunto que julgamos importante é que, quase sempre são neces- 
sários para detectar situações anormais no trabalho, instrumentos de alerta, que são mencionados na publicação número 1 e não são mencionados na publicação número 9, grande falha.

A seguir discutiremos as informações observadas durante $O$ confronto das publicações número 9 da ICRP e número 9 do IAEA. Com relação a limitação da dose para o público, A publicação 9 da ICRP é mais extensa a respeito dos indivíduos do público do que aquela do IAEA, fornecendo as seguintes informações omitidas pelo do IAEA:

- Crianças em idade inferior a 16 anos tem seu limite anual de dose diminuído para 1,5 rem/ano em vez de $3 \mathrm{rem} / \mathrm{ano}$.

- Define grupo crítico para os indivíduos do público e informa que os limites de dose se aplicam a ele.

- Exames médicos em mulheres com capacidade de reprodução, envolvendo radiação ionizante, devem ser realizados, na medida do possível, nos primeiros 10 dias após o começo da menstruação. Seguiremos agora discutindo o confrontamento da publicação número 2 da ICRP e de número 30, também da ICRP.

Ambas as publicações se dedicam nos ajudar em diversos cálculos de dose em diversos órgãos. A grande diferença observada entre elas é que na publicação número 2 obtêm-se o resultado de dose absorvida no ano da exposição, porém, nestes cálculos nãos estão inclusas as doses que provem da mesma exposição no decorrer dos anos, para isto deveria ser feito um novo cálculo. A publicação número 30 supera este dilema, incluindo em seus cálculos as possíveis doses decorrentes da mesma exposição para os anos que seguem, porém, esta dose não é registrada de forma fracionada durante os anos em que o indivíduo receberia esta dose e sim no mesmo ano da exposição. O que consequentemente prejudica ao registrar a dose anual do trabalhador, pois fica entendido que a dose que ele estará recebendo no decorrer dos anos ele recebeu em um único ano. 
Passaremos agora a uma análise entre as publicações número 1, 2 e 9 da ICRP e 9 do IAEA edição de 1967, que seguem a Filosofia dos Limites Anuais Máximos Permissíveis (LAMP) com as publicações também da ICRP 26 e 30, que seguem a nova Filosofia, que a chamaremos de Limites Anuais Máximos Admissíveis (LAMA) para facilitar o estudo. Antes de discutirmos a nova filosofia devemos estabelecer como premissa o porquê se tornou necessária a sua mudança. Uma série de fatos propiciaram esta mudança, mas dentre eles destacaremos alguns que consideramos vitais:

Os efeitos biológicos considerados completamente aleatórios, como os cânceres e o encurtamento da vida, na realidade não eram tão aleatórios e imprevisíveis assim, mas obedeciam as leis das probabilidades e da estatística. O encurtamento da vida não pode ser provado para os seres humanos e deixou de ser considerado. Para explicar o aparecimento dos cânceres induzidos pela radiação ionizante surgiu a teoria alvo. Em síntese, esta teoria está alicerçada no tiro ao alvo pela qual o tiro seria a radiação ionizante e o alvo a célula. Se o tiro, radiação ionizante, acertasse a célula em seus pontos vitais, ela morreria, mas em caso contrário poderia ser lesada e vir a morrer tempo depois ou sobreviver, ao ferimento. Neste último caso poderia ser, em virtude da lesão, uma célula diferenciada das demais e se o patrimônio de divisão celular não for prejudicado dar origem a descendentes diferenciados que após várias gerações de divisão apareceriam clinicamente diagnosticáveis como câncer. Como qualquer radiação ionizante, por menor energia que tenha, é suficiente para lesar as células, devemos admitir que o processo oncogênese é sem limiar, ou em outras palavras, qualquer dose por menor que seja faz mal e, portanto, deve ser reduzida. Para conseguir a redução de dose deveria se modificar a filosofia do Sistema de Limitação de Dose, isto é, devemos melhorar as condições de proteção até chegarmos a um valor de dose cujo risco, por ser considerado 
muito pequeno, é aceitável. Este valor de risco é conhecido como nível de registro.

Em segundo lugar quando surgiu a primeira publicação de $\mathrm{n}-\underline{0}$ 22 (6) da ICRP estávamos em plena crise do petróleo que trouxe uma série de consequências econômicas mundiais muito graves. Este fato, também, deveria ser levado em consideração e, portanto, propiciou a introdução da nova filosofia, LAMA.

O novo sistema de limitação estabelece os limites anuais máximos admissíveis, LAMA, para o trabalhador e para o público. O limite da população como um todo foi eliminado uma vez que foi analisada a dose dos grupos críticos recebidas nos países mais desenvolvidos e todas elas apresentavam doses iguais ou inferiores a $1 \mathrm{mSv} / \mathrm{a}$ e uma dose média de $0,5 \mathrm{mSv} / \mathrm{a}$ e, portanto, o valor estipulado para a população como um todo nunca seria alcançado.

Estes limites anuais só são admitidos se forem justificados e enquanto se mantiverem otimizados. Doses superiores aos LAMA para trabalhadores e indivíduos do público são inaceitáveis. O princípio da justificação e principalmente o princípio da otimização, isto é, que as doses devem ser mantidas otimizadas é que nos fazem com que a proteção seja cada vez melhorada até alcançarmos os valores de dose considerados aceitáveis. O princípio da justificação nos proíbe a introdução de atividades para as quais o prejuízo sanitário é superior ao benefício recebido pela sociedade com a introdução daquela atividade e o princípio da otimização também conhecido como princípio ALARA "as low as reasonable achievable", tão pequenas quanto racionalmente exequível, nos impõe a diminuição contínua das doses

Discutiremos agora alguns assuntos pertinentes originados do confronto entre as publicações número 26 e 30 da ICRP contra a publicação número 9, edição de 1982 do IAEA. Um dos fatores que julgamos pertinente mencionar entre estas publicações 
é referente as categorias de exposição. Nas publicações 26 e 30 as categorias de exposição tornam a mudar, e são: Exposições Ocupacionais; Exposições Médicas e Outras exposições. Com familiaridade com a primeira categoria falaremos um pouco da segunda, que obriga o uso dos princípios de proteção radiológica, justificação, otimização e limitação da dose, para estas exposições, exceto para o público. O IAEA, em sua publicação de número 9, edição de 82, não comenta a respeito destas categorias, deixando pré suposto que são as mesmas da ICRP, porém durante os artigos que tratam de limites de dose ele entra profundamente em outro assunto, que são os tipos de limites: Primários, secundários, derivados e autorizados, mas não enfatizam estas categorias descritas pela ICRP.

Passaremos agora a citar alguns itens de interesses encontrados no confrontamento da publicação de número 60 da ICRP e a 115 do IAEA. Dentre inúmeros assuntos, julgamos pertinente discorrer sobre os Efeitos Biológicos, onde na publicação $n^{\circ} 60$ nos são apresentados vários estudos nos laboratórios de todo o mundo que resultaram em uma riqueza de informações concernentes aos efeitos biológicos das radiações em número muito maior do que aqueles associados a qualquer outro perigo ambiental. Assim ela divide estes efeitos biológicos em dois, a saber: Efeitos determinísticos e Efeitos Estocásticos. O IAEA por sua vez descreve os mesmos dois feitos, porém ele discute um terceiro efeito, o qual ele denomina de Outros Efeitos a Saúde, que podem ocorrer em crianças devido a exposição do embrião ou do feto.

Por fim, do estudo comparativo entre as publicações número 103 da ICRP e GSR parte III do IAEA, onde esta última apresenta uma série de exigências a serem cumpridas, exigências estas nos quais poucas se encontram implícitas na publicação da ICRP. A grande vantagem é que na publicação do IAEA tudo se encontra organizado por assunto possibilitando fácil consulta, diferente 
da ICRP, onde o leitor deveria ler todo o capitulo para ter uma noção de como proceder.

\section{CONCLUSÃo}

É uma tarefa árdua seguir apenas um dos órgãos competentes, ficou evidente que os estudos realizados pela ICRP, que envolve principalmente os aspectos de proteção e segurança, diferem daqueles utilizados pelo IAEA, que visa a regulamentação de uma instalação e os padrões regulamentadores. O acordo entre o IAEA e a ICRP tornou impossível para o gerente de quaisquer serviço radiológico ou instalação basear-se apenas nas normas do IAEA, pois tudo o que diz respeito a radiobiologia está descrito nas recomendações da ICRP, os quais o IAEA adota, porém não publica em suas normas e também não os referência. Ainda assim notamos que corriqueiramente o IAEA fala sobre assuntos que diz respeito a proteção radiológica, de maneira a complementar algo que a ICRP deixou de dizer, para que assim satisfaça seus critérios.

Foi observada a maneira ao qual os assuntos são apresentados, a ICRP costuma a trazer textos ou muito longos, ou muito resumidos e para aqueles temas aos quais a Comissão julga necessária uma revisão (para aquilo que ela mesmo diz) ela cita "estudos em andamento", dos quais acabam não aparecendo em publicações seguintes. Por outro lado, apesar de não apresentar seus assuntos de forma básica, como faz a ICRP o IAEA mostra-se muito mais prático, não mostrando tantos texto, e sim tópicos, que servem como guia de consulta rápida, mas nem sempre satisfazem a necessidade e o entendimento do leito.

$\mathrm{Na}$ questão das substituições e supressões que foram encontradas por parte da ICRP em suas publicações, acreditamos que signifique pura falha dos confeccionadores das publicações, devido a rotativi- 
dade desta equipe, que sempre muda a cada publicação, mudando assim várias ideias e ponto de vista, bem como a afinidade por diversos assuntos.

\section{Referências}

International Commission on Radiological Protection, Recommendations of the International Commission on Radiological Protection, 1958, (ICRP Publication 1).

International Commission on Radiological Protection, Report of Committee II on Permissible Dose for Internal Radiation, 1959, (ICRP Publication 2).

International Commission on Radiological Protection, Recommendations of the International Commission on Radiological Protection, 1966, (ICRP Publication 9).

International Atomic Energy Agency. Basic Safety Standards for Radiation Protection, Vienna, 1967. (Safety Series No. 9)

International Commission on Radiological Protection, Implications of commission Recommendations that Doses be kept as Low as Readily Achievable, 1973, (IRCP No. 22)

International Commission on Radiological Protection, Recommendations of the International Commission on Radiological Protection, Annals of the ICRP Vol. I No. 03, 1977, (ICRP 26)

International Commission on Radiological Protection, Limits for Intakes of Radionuclides by Workers. Oxford, Pergamon, 1978 a 1980, (ICRP 30)

International Atomic Energy Agency. Basic Safety Standards for Radiation Protection, Vienna, 1982 edition. (Safety Series No. 9)

International Commission on Radiological Protection, 1990 recommendations of the International Commission on Radiological Protection, Oxford, Pergamon, 1991, (ICRP 60)

International Atomic Energy Agency. International Basic Safety Standards for Protection Against Ionizing Radiation and for the Safety of radiation Sources - A Safety Standard, Vienna, 1997, (Safety Series No. 115)

International Commission on Radiological Protection, the 2007 Recommendations of the International Commission on Radiological Protection, 2007, (ICRP 103)

International Atomic Energy Agency. Radiation Protection and Safety of Radiation Sources: International Basic Safety Standards - Interim Edition, Vienna, 2011, (No. GSR Part 3 - Interim) 